\title{
Design and application of environmentally effective concrete with usage of chrysotile- cement waste
}

\author{
Lada Egorova ${ }^{1, *}$, Vyacheslav Semenov ${ }^{1}$, Anna Pligina ${ }^{1}$, Aizat Askhadullin ${ }^{1}$ \\ ${ }^{1}$ Moscow State University of Civil Engineering, Yaroslavskoye Sh., 26, Moscow, 129337, Russian \\ Federation
}

\begin{abstract}
Construction is resource-demanding industry, characterized by a large volume of waste. Particularly chrysotile cement waste obtained both in production and in dismantling over age chrysotile-cement products: corrugated asbestos boards and flat sheets, chrysotile-cement tubes. We propose to use dry chrysotile-cement waste as recycled aggregate for concrete. Based on developed compositions and identified properties of heavy concrete with chrysotile-cement waste introduce this technology to the production of foundation wall blocks. The studies confirmed the possibility of using chrysotile-cement aggregate and fine screening of crushing as a secondary coarse and fine aggregates for concrete with proper quality without increasing the cost of the product. Environmental safety of the obtained products was ensured. The direction for implementation of the research project was proposed.
\end{abstract}

\section{Introduction}

Nowadays experts of various spheres of business, including construction, design solutions to environmental pollution problems. Construction is resource-demanding industry, characterized by a large volume of waste [1-3]. Particularly during the existence of the asbestos cement industry in the Soviet Union and then in Russian Federation, there is appeared a problem of recycling chrysotile cement waste obtained both in production and in dismantling over age chrysotile-cement products: corrugated asbestos boards and flat sheets, chrysotile-cement tubes. According to Rosstat, in 2014 it produced 793,000 tons chrysotile-cement products, and waste volumes at chrysotile-cement products factories amounted to 80000 tons.

\section{Problem statement}

Among the modern methods of recycling, we could highlight the use of wet waste in the production of building materials with their mechanochemical activation mainly offered in Russia. As well as developed abroad methods for chrysotile-cement waste utilization by of

\footnotetext{
${ }^{*}$ Corresponding author: EgorovaLV93@gmail.com
} 
heat treatment to fully crystal-chemical transformation of asbestos fibers, with subsequent disposal or use in the production of cement, ceramic, etc. [4-8]. The existing methods of their utilization are energy-intensive and expensive. Therefore, it calls into question the rationality of such technologies. We propose to use dry chrysotile-cement waste as recycled aggregate for concrete mixes. It will free up landfill area of and broaden raw material base of building materials, thus contributing to solve important environmental and economic problems [3-8].

The aim of research is to develop compositions and to identify properties of heavy concrete with chrysotile-cement waste (scrap and fine screening of crushing) for introduction this technology to the production of foundation wall blocks.

\section{Materials and methods}

From scrap chrysotile-cement flat sheets we obtained secondary coarse aggregate and identified its strength and performance properties. Mean density $-2028 \mathrm{~kg} / \mathrm{m}^{3}$, bulk density $-843 \mathrm{~kg} / \mathrm{m}^{3}$, the emptiness of material $-58.4 \%$, the water absorption by weight $-19.2 \%$, and the water absorption by volume $-38.9 \%$.

A by-product during the fragmentation of the scrap became fine screening which contain sand and dust-like fractions. An analysis of grain composition graph of fine screening (Figure 2) showed the possibility of its reuse as the secondary fine aggregate.

The value of true specific density $-2400 \mathrm{~kg} / \mathrm{m}^{3}$; bulk density $-940 \mathrm{~kg} / \mathrm{m}^{3}$, water demand $-10.5 \%$, fineness modulus -2.93 .

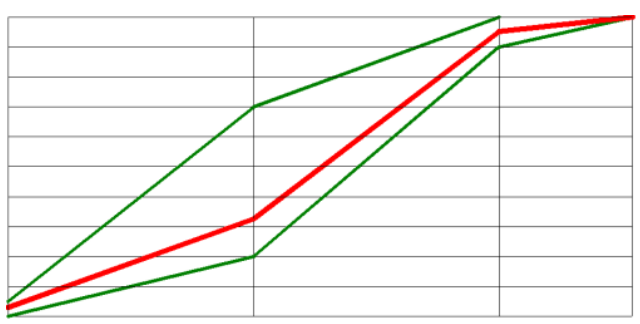

Fig. 1. Grain composition graph of coarse chrysotile-cement aggregate.

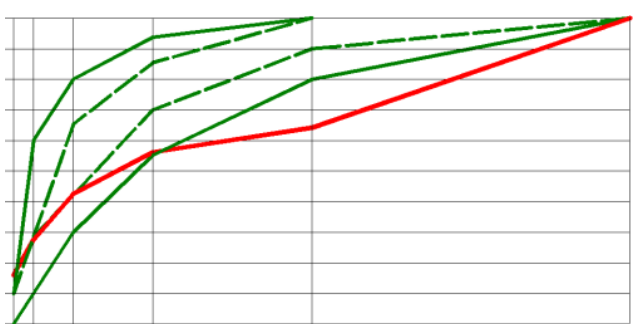

Fig. 2. Grain composition graph of fine chrysotile-cement aggregate.

X-ray diffraction analysis (Figure 3) revealed the existence of cement minerals. Mineral composition of fine screening consists of chrysotile asbestos, product of Portland cement hydration, calcspar, cement minerals. Strength test of samples made from mixing screening with water showed that dust approves cementing properties. Ultimate bending strength of samples- 0.85 MPa, ultimate compressive strength - 3.9 MPa.

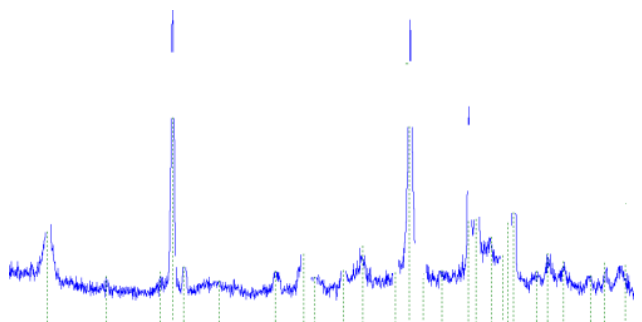

Fig. 3. X-ray diagram of cc fine aggregate.

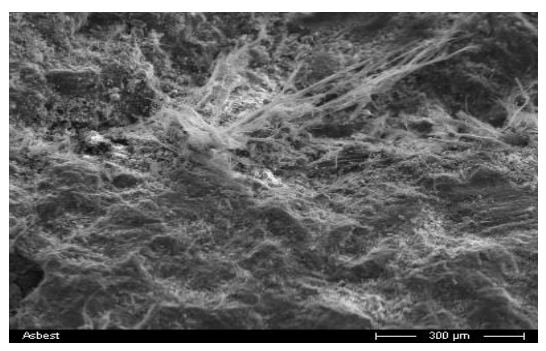

Fig. 4. Microstructure of coarse chrysotilecement aggregate. 


\section{Calculation of concrete mixture}

The composition of concrete was calculated with usage of law of concrete strength formula and absolute volume equation taking into account the increased water demand of secondary aggregates and their proportion in the whole mass of aggregate. The basic concrete composition with coarse chrysotile-cement aggregate calculated for concrete class B15, with fine aggregate - B20. As binding substance was taken Holcim Portland cement with slag CEM II / B-SL $32.5 \mathrm{~N}$, fine aggregate - silica sand with average grain size, coarse aggregate - granite rubble fractions 5-20 $\mathrm{mm}$. To reduce actual water consumption we used superplasticizer C-3.

\section{Results and discussion}

Properties of concrete with different contents of recycled coarse and fine aggregate were investigated. Concrete samples with replacement from $9 \%$ to $100 \%$ of crushed granite to coarse secondary aggregate were prepared. Next, we made samples with replacement from $10 \%$ to $50 \%$ of sand to fine aggregate.

Table 1. Compositions and properties of concrete with usage secondary coarse aggregate.

\begin{tabular}{|c|c|c|c|c|c|c|c|}
\hline & \multirow[t]{2}{*}{ Features } & \multirow{2}{*}{$\begin{array}{l}\text { Control } \\
\text { comp. }\end{array}$} & \multicolumn{5}{|c|}{$\begin{array}{l}\text { The share of CC aggregate in all } \\
\text { coarse aggregate }\end{array}$} \\
\hline & & & 9 & 23 & 33 & 50 & 100 \\
\hline \multirow{6}{*}{$\begin{array}{c}\text { The } \\
\text { composition } \\
\text { of concrete } \\
\text { per } \mathrm{m}^{3}, \mathrm{~kg}\end{array}$} & Portland cement & 213 & 227 & 244 & 256 & 285 & 323 \\
\hline & Water & 160 & 170 & 183 & 192 & 214 & 242 \\
\hline & Sand & 754 & 786 & 827 & 842 & 842 & 873 \\
\hline & $\begin{array}{c}\text { Coarse granite } \\
\text { aggregate }\end{array}$ & 1285 & 1075 & 809 & 652 & 432 & 0 \\
\hline & CC coarse aggregate & 0 & 107 & 243 & 326 & 432 & 658 \\
\hline & $\begin{array}{l}\text { Superplasticizing } \\
\text { admix C-3 }\end{array}$ & 1.6 & 1.7 & 1.8 & 1.9 & 2.2 & 2.4 \\
\hline \multicolumn{2}{|c|}{ Medium density, $\mathrm{kg} / \mathrm{m}^{3}$} & 2425 & 2395 & 2280 & 2310 & 2235 & 2120 \\
\hline \multicolumn{2}{|c|}{$\begin{array}{l}\text { Compressive strength of concrete, } \\
\mathrm{MPa}\end{array}$} & 19.5 & 22.6 & 21.5 & 22.2 & 26.8 & 27.3 \\
\hline \multicolumn{2}{|c|}{ Strength-to-weight ratio, $\mathrm{MPa}$} & 8.0 & 9.4 & 9.4 & 9.6 & 12.0 & 12.9 \\
\hline \multicolumn{2}{|c|}{ Water absorption, $\%$} & 2.9 & 3.0 & 3.2 & 3.3 & 3.6 & 3.9 \\
\hline \multicolumn{2}{|c|}{ Frost resistance } & 300 & 300 & 300 & 300 & 300 & 300 \\
\hline \multicolumn{2}{|c|}{ The cost of materials per $1 \mathrm{~m}^{3}$, } & 4053 & 4045 & 4034 & 4025 & 4027 & 4008 \\
\hline
\end{tabular}

With increase of content of secondary porous aggregate in concrete, the average density of the concrete reduces, but the strength increases up to $40 \%$. Accordingly, the specific strength of concrete with chrysotile-cement coarse aggregate increases up to $60 \%$ compared to the control composition.

This effect is due to increased consumption of cement, because it is necessary to ensure constant water-cement ratio.

Note that coarse porous chrysotile-cement aggregate plays a positive role in the concrete structure formation. By absorbing water at the initial stage of hardening, it consolidates contact area "hardened cement paste - concrete aggregate". Then giving the absorbed water during the concrete consolidation it leads to increased degree of hydration of cement. 
Table 2. Compositions and properties of concrete with usage secondary fine aggregate.

\begin{tabular}{|c|c|c|c|c|c|}
\hline \multirow{2}{*}{\multicolumn{2}{|c|}{ Features }} & \multirow{2}{*}{$\begin{array}{l}\text { Control } \\
\text { comp. }\end{array}$} & \multicolumn{3}{|c|}{$\begin{array}{c}\text { The share of CC fine } \\
\text { aggregate }\end{array}$} \\
\hline & & & 10 & 30 & 50 \\
\hline \multirow{6}{*}{$\begin{array}{c}\text { The } \\
\text { composition } \\
\text { of concrete } \\
\text { per } \mathrm{m}^{3}, \mathrm{~kg}\end{array}$} & Portland cement & 231 & 260 & 290 & 328 \\
\hline & Water & 146 & 164 & 183 & 207 \\
\hline & Sand & 682 & 582 & 411 & 265 \\
\hline & Gravel & 1351 & 1318 & 1258 & 1193 \\
\hline & CC fine aggregate & 0 & 65 & 176 & 266 \\
\hline & Superplasticizing admix C-3 & 1.7 & 1.9 & 2.2 & 2.5 \\
\hline \multicolumn{2}{|c|}{ Medium density, $\mathrm{kg} / \mathrm{m}^{3}$} & 2410 & 2390 & 2320 & 2260 \\
\hline \multicolumn{2}{|c|}{ Compressive strength of concrete, $\mathrm{MPa}$} & 27.6 & 26.9 & 28.3 & 33.1 \\
\hline \multicolumn{2}{|c|}{ Strength-to-weight ratio, $\mathrm{MPa}$} & 11.4 & 11,3 & 12,2 & 14.6 \\
\hline \multicolumn{2}{|c|}{ Water absorption , \% } & 2.9 & 3.0 & 3.5 & 3.8 \\
\hline \multicolumn{2}{|c|}{ Frost resistance } & 300 & 300 & 300 & 300 \\
\hline \multicolumn{2}{|c|}{ The cost of materials per $1 \mathrm{~m}^{3}$, } & 4084 & 4117 & 4068 & 4061 \\
\hline
\end{tabular}

As in the case of coarse secondary aggregate, higher water demand of fine aggregate also leads for increase of cement consumption. In case of replacement up to $50 \%$ of sand to chrysotile-cement fine aggregate the actual increase of cement consumption will amount up to $42 \%$. However, the actual consumption of coarse aggregate is reduced by $11 \%$, sand $61 \%$. The average density of the concrete is reduced by $6 \%$ and the compressive strength increases by $20 \%$. CC fine aggregate exercises cementing properties and contributes to increase strength of concrete.

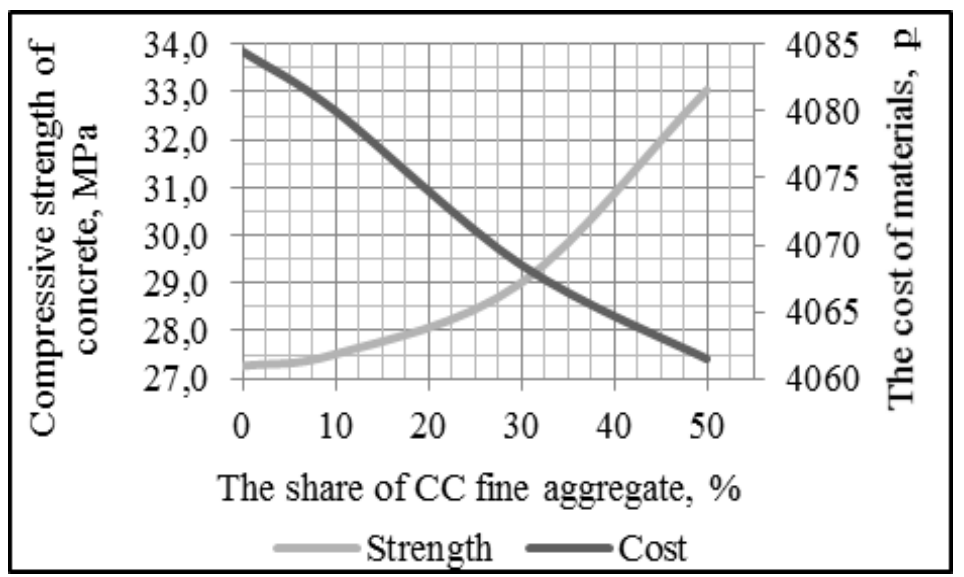

Fig. 5. The graph of the compressive strength of concrete and the cost, depending on the share of fine chrysotile-cement aggregate. 


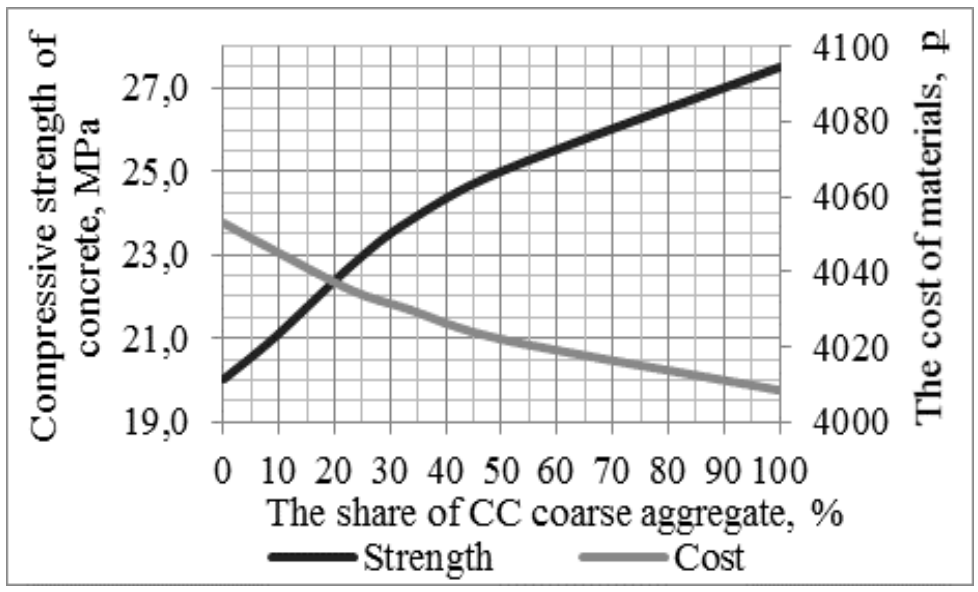

Fig. 6. The graph of the compressive strength of concrete and the cost, depending on the share of coarse chrysotile-cement aggregate.

\section{Assessment of environmental safety}

There are several scientific publications, which shows the possibility of the safe usage of chrysotile-cement $[10,11]$. Opening chrysotile fibers due to mechanical damage are covered with products of hydration and subsequent carbonization of cement and have a reduced biological activity. The usage of dry chrysotile-cement waste as aggregate excludes fiber emission due to its dual "conservation" by the concrete. Foundation blocks during operation are located in the ground, the negative impact of fiber by respiratory route on human is impossible.

We additionally carried out an environmental assessment of the resulting material and technology in general. The radiological examination of chrysotile-cement aggregate and concrete with secondary aggregate was made. The effective specific activity of natural radionuclides suits for Russian regulation norms. Fiber emission from the concrete and from coarse chrysotile-cement aggregate tests in repeated freeze-thaw in the water, in solution of magnesium chloride and sulfuric acid, which conforms to sulphate, magnesia and chloride high corrosive ground for concrete waterproofing capacity W4. During microscope analysis, emitted chrysotile asbestos fibers were not observed in filtration residues (Fig. 7.). Furthermore, we decided to determine the frost resistance of the obtained samples. According to Russian norms of methods for determination of frost resistance on the basis of 37 cycles performed 3 accelerated method obtained mark on frost resistance 300 . Reducing weight of concrete samples was less than $2 \%$. 


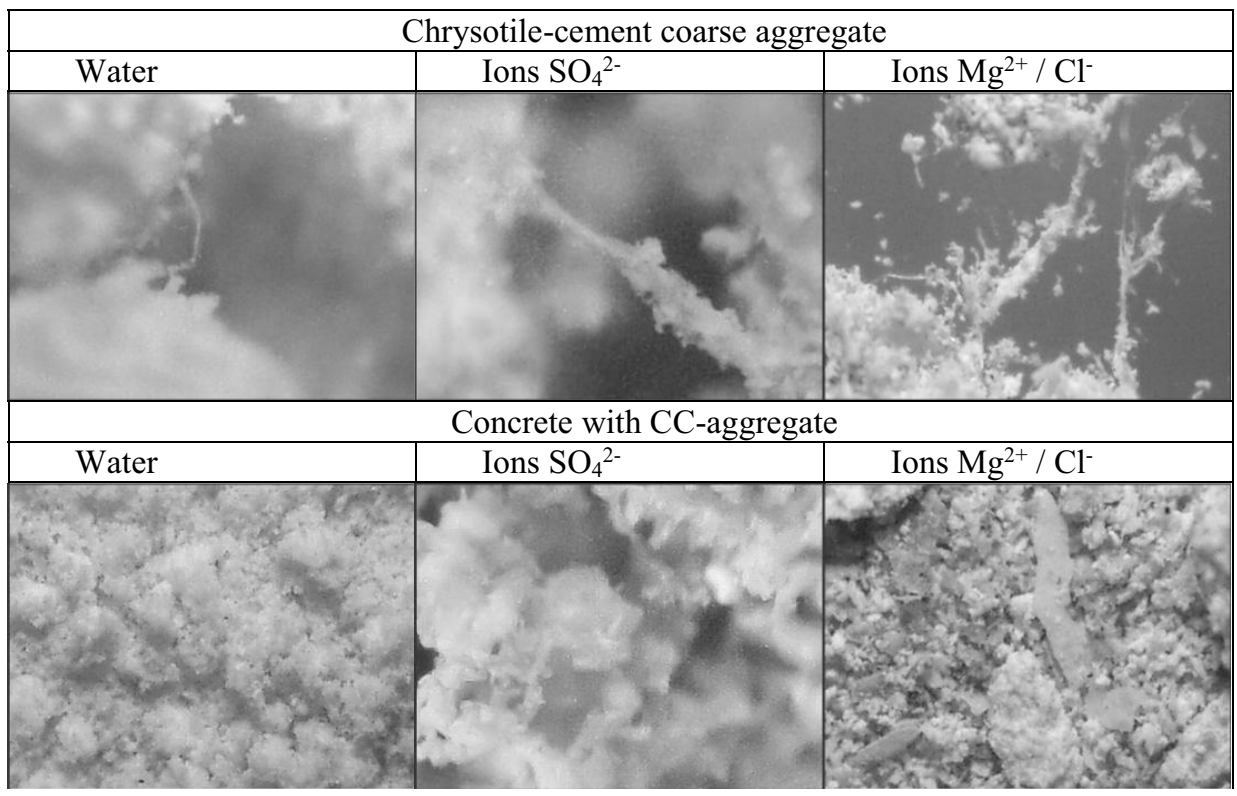

Fig. 7. The degree of influence of high corrosive ground at fiber emission.

\section{Conclusions}

Increased water demand of chrysotile-cement aggregate leads to increase water and cement consumption. In the same time, the consumption of other concrete components reduced. Comparing the market prices for concrete components, we can see that the usage of such chrysotile-cement waste allows us to obtain concrete without increasing the cost of the product. The usage of chrysotile-cement waste allows obtaining concrete in the range of the required strength of $15 \ldots 30 \mathrm{MPa}$ depending on the proportion of secondary aggregates and cement consumption. Factory production of some types of products contributes the complete replacement of natural aggregates by chrysotile-cement aggregates without reducing products' physical, mechanical and exploitation properties.

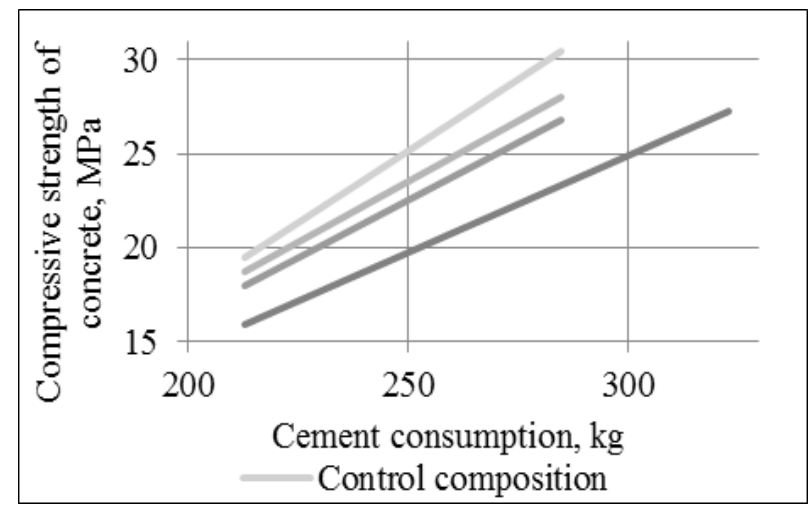

Fig. 8. The graph of the strength of concrete, depending on the flow of cement, grade 32.5 . 
As result of research, the effective concrete with chrysotile-cement waste was developed and environmental safety was confirmed. Environmental effectiveness of technology consist in comprehensive utilization of chrysotile-cement waste: coarse aggregate - gravel and fine screening of crushing. The research results are presented for "Chrysotile association" and received positive feedback from the chrysotile industry.

The inactivity of construction industry in relation to new technologies and materials, normative limitations of the use of waste, ensuring uninterrupted receipt of secondary resources and uniformity of product properties, and justification of economic efficiency of developments complicate the implementation of waste management technologies in the production process.

The development of starting local manufacturing heavy concrete with chrysotile-cement waste in chrysotile-cement products factories is more expedient because large concrete manufacturers have their own long-standing supply lines of traditional aggregates [12]. Eventually based on formed experience introduce this technology to the production of foundation wall blocks [3, 9].

Concluding all, we propose to implement the following plan for technology realization in the construction industry:

1. Evaluation of chrysotile-cement waste volumes at a specific landfill or a chrysotilecement -products factory dump.

2. Making a treaty about delivery chrysotile-cement waste with companies which dismantle buildings.

3. Obtaining scrap and fine screening by crushing and sorting chrysotile-cement waste.

4. Creating a production line and certification of products.

5. The introduction of products to the market.

\section{References}

1. D.V. Oreshkin, Construction materials 11, 6 (2010)

2. D.V. Oreshkin, K.N. Popov, A.I. Liljak, A.G. Mezhov, Vestnik MGSU-MSUCE Herald 2, 296-298 (2011)

3. V.S. Semenov, A.I. Pligina, T.A. Rozovskaya, Materials Science and Engineering 012041, 71 (2015)

4. V.V. Kozlov, K.N. Popov, A.G. Mezhov, A.I. Liljak, Vestnik MGSU - MSUCE Herald 2, 284-287 (2011)

5. P.P. Gujumdzhjan, M.L. Kashnikova, T.N., Construction materials 9, 20-21 (2006)

6. M. Radvanec, L. Tuček, J. Derco, K. Čechovská, Z. Németh, Journal of Hazardous Materials 252-253, 390-400 (2013)

7. T. Prasauskas, D. Martuzevicius, E. Krugly, L. Kliucininkas, M. Kireitseu, A. Zerrath., Building and Environment 46, 2295-2302 (2011)

8. A.F. Gualtieri, C. Cavenati, I. Zanatto, M. Meloni, G. Elmi, M. Lassinantti Gualtieri, Journal of Hazardous Materials 152, 563-570 (2008)

9. A.I. Pligina, V.S. Semenov, L.V. Egorova, A.A. Ashadullin, Science Review 2, 84-88 (2015)

10. N.S. Makarova, S.V. Kashansky, E.G. Plotko, Construction materials 9, 19-20 (2001)

11. S.M. Nejman, I.G. Luginina, A.I. Vezencev, V.V. Turskij, L.N. Naumova, L.L. Nesterova, A.I. Gorshkov, A.V. Sivcov, Construction materials 4, 30-31 (2002)

12. G.G. Lunev, Internet Journal Naukovedenie 3, 22 (2014) 